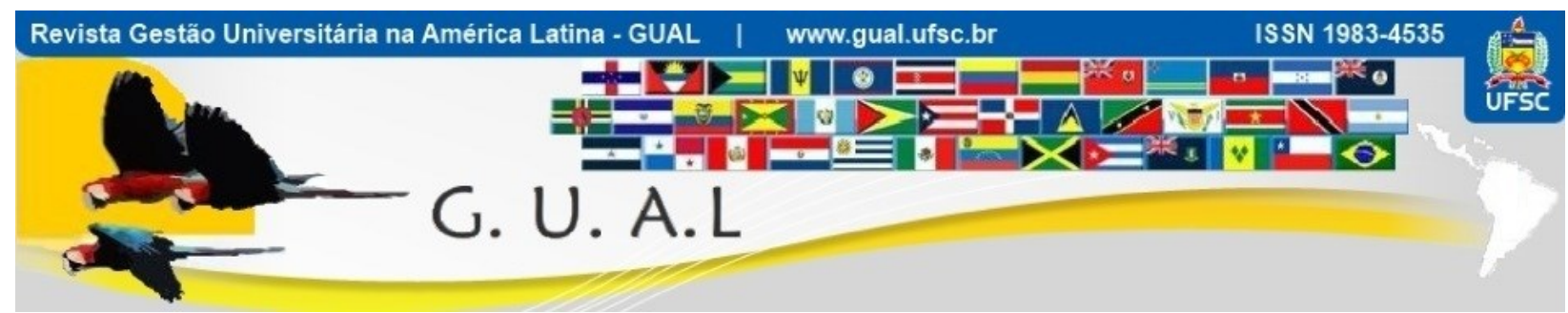

DOI: http://dx.doi.org/10.5007/1983-4535.2016v9n2p49

\title{
A PRESENÇA DE DOCENTES MULHERES EM CARGOS GERENCIAIS NAS UNIVERSIDADES FEDERAIS DO ESTADO DE MINAS GERAIS
}

\author{
THE PRESENCE OF THE WOMEN INSTRUCTORS AT MANAGEMENT \\ POSITIONS ON UNIVERSITIES IN THE FEDERAL STATE OF MINAS GERAIS
}

Rafaela Fernanda Barbosa de Siqueira, Graduada

Universidade Federal de Alfenas - UNIFAL-MG rafaelabasi@gmail.com

Adílio Renê Almeida Miranda, Doutor Universidade Federal de Alfenas - UNIFAL-MG adilioadm@yahoo.com.br

Fernanda Teixeira Franco Ribeiro, Especialista Universidade Federal de Lavras - UFLA fernandafrancoribeiro@hotmail.com

Mônica Carvalho Alves Cappelle, Doutora Universidade Federal de Lavras - UFLA edmo@dae.ufla.br

Recebido em 24/junho/2014

Aprovado em 22/outubro/2015

Sistema de Avaliação: Double Blind Review

Esta obra está sob uma Licença Creative Commons Atribuição-Uso. 


\title{
RESUMO
}

A presença da mulher no meio produtivo é um movimento que se acentuou nas últimas décadas. Contudo, alguns estudos sobre as relações de gênero têm evidenciado que esse movimento não ocorre em todas as áreas e posições nas organizações. Assim, este estudo teve como objetivo analisar a presença de docentes mulheres em cargos gerenciais nas universidades federais do estado de Minas Gerais. Para tanto, realizou-se uma pesquisa de natureza quantitativa de caráter descritivo, na qual os dados foram coletados a partir de fontes secundárias e analisados por meio da distribuição de frequência. Foi possível identificar que, nas universidades federais pesquisadas, a maioria dos cargos gerenciais é ocupada por docentes homens, principalmente, em cargos de alto nível hierárquico. Verificou-se, também, que a ascensão na carreira das docentes ainda pode ser limitada ou direcionada, ou seja, voltada para as áreas em que elas já estão em maior número. Finalmente, pode-se dizer que a inserção de docentes mulheres em cargos gerenciais nas universidades federais de Minas Gerais ainda não ocorreu nas mesmas proporções que a inserção delas nas universidades, em cursos de pós-graduação e como docentes.

Palavras-chave: Gerência universitária. Mulheres na gestão. Universidades de Minas Gerais.

\begin{abstract}
The presence of the woman in the labor market is a movement that accented through the decades. However, some studies about gender relations have shown that this movement don't occur in any organizations areas and positions. So, this study had the objective to analise the presence of the women instructors at management positions on federal universities in the state of Minas Gerais. Thereby, a qualitative research was conducted, in which the data were collected through secondary fonts and analysed by frequency distribution. It was possible to indetify that, in the federal universities in which the survey occurred, most management roles are occupied by men instructors, mainly in high-level hierarchical positions. It was possible to verify, as well, that the ascension at the instructors career can be limited or directed, in other words, focused in areas where they already are a majority. Lastly, it's possible to say that the insertion of women instructors in management roles at federal universities in the state of Minas Gerais still haven't occurred in the same proportions as their insertion in the universities, in postgraduate courses and as instructors.
\end{abstract}

KeyWords: University management. Woman in management. Universities of Minas Gerais. 


\section{A PRESENÇA DE DOCENTES MULHERES EM CARGOS GERENCIAIS NAS UNIVERSIDADES

\section{INTRODUÇÃO}

A presença da mulher no meio produtivo é um movimento que se acentuou nas últimas décadas, impulsionada, em grande parte, pelas alterações sociais, econômicas e culturais que ganharam força no século XX (ARAÚJO, 2005). Fatores como a queda na taxa de fecundidade, a expansão na escolaridade e o aumento no número de divórcios podem ter contribuído para que as mulheres, além de cuidarem dos afazeres de casa e dos filhos, passassem também a ter uma relação com trabalho fora do lar, cada vez mais estreita (FONSECA, 1996; BRUSCHINI, 2007). Esse movimento se deve, principalmente, aos movimentos feministas, à luta das mulheres e mudanças de valores na sociedade, que colaboraram para ampliar as possibilidades de ocupação das mulheres no mercado de trabalho, inclusive, em funções e posições com maior concentração de homens, como por exemplo, em cargos gerenciais. Entretanto, em uma pesquisa realizada em empresas que atuam no Brasil, Neto et. al. (2010, p.12) observaram que posições mais altas são pouco ocupadas por mulheres. Segundo os autores, "quanto mais se sobe na hierarquia empresarial, menos mulheres são encontradas" em cargos gerenciais, indicando, assim, que este espaço ainda tende a ter predominância de homens.

No contexto de setor público, há algumas diferenças em relação ao setor privado nas questões de gênero, quanto a salários e promoções (PUPPIN, 1995). O ingresso no serviço público ocorre por meio de concurso, o que, no primeiro momento, auxilia na diminuição das desigualdades de gênero, contribuindo para a entrada da mulher em organizações públicas de forma mais igualitária. Contudo, há cargos que são comissionados, ou seja, por indicação de um superior, geralmente, cargos de alta gerência. Diante disso, podem ocorrer disparidades na ocupação de postos de maior prestígio da organização, como identificado por Miranda (2010), em sua pesquisa nas universidades federais de Minas Gerais, segundo a ocupação de cargos de nível alto (pró-reitoria e chefia de gabinete). O estudo verificou que esses cargos eram compostos por quase três vezes mais docentes homens $(72,15 \%)$ do que por docentes mulheres (27,85\%). Assim, na gestão universitária dessas instituições, docentes mulheres ainda representam uma pequena parcela nas altas posições hierárquicas.

Por outro lado, percebe-se que há um aumento de mulheres na área acadêmica e no campo da pesquisa, que também pode demonstrar uma tendência no aumento de docentes mulheres em universidades. Segundo dados da base de currículos Lattes de 2013, o percentual de doutores foi de 53,2\% e doutoras, $46,8 \%$. Das mulheres com doutorado, 36,2\% são da área 


\section{A PRESENÇA DE DOCENTES MULHERES EM CARGOS GERENCIAIS NAS UNIVERSIDADES \\ FEDERAIS DO ESTADO DE MINAS GERAIS \\ DOI: http://dx.doi.org/10.5007/1983-4535.2016v9n2p49}

de saúde e biológicas, $29,7 \%$ de Humanas ${ }^{1}$. Em contrapartida, nas áreas de agrárias e engenharias, elas representam 8,8\% e 5,2\%, respectivamente (CNPQ, 2014). Tais dados revelam que a diferença numérica entre homens e mulheres com doutorado não é tão marcante, entretanto, mostra que elas ainda têm se concentrado nas áreas tradicionalmente femininas. Nesse sentido, cabe uma importante reflexão, o aumento do número de mulheres com doutorado e, ao mesmo tempo, sua inserção como docentes nas universidades federais de Minas Gerais, tem ocorrido também na ocupação de cargos gerenciais nessas universidades?

Assim, pretendeu-se com esta pesquisa analisar a presença de docentes mulheres em cargos gerenciais nas universidades federais do estado de Minas Gerais.

A presente pesquisa foi estruturada apresentando, inicialmente, a discussão conceitual que trata da construção social do gênero. Em seguida, questões sobre a mulher e o trabalho são apontadas, contemplando as dificuldades/desafios e avanços nesse cenário, juntamente com alguns conceitos, como a segregação ocupacional. Por fim, é apresentada a metodologia utilizada, as análises realizadas e as considerações finais.

\section{REFERENCIAL TEÓRICO}

\subsection{A CONSTRUÇÃO SOCIAL DAS RELAÇÕES DE GÊNERO: GUETOS, ESTEREÓTIPOS E PAPÉIS LIGADOS AO FEMININO E AO MASCULINO}

Considerando as discussões conceituais sobre gênero, para Scott (1995, p. 21), gênero "é um elemento constitutivo de relações sociais baseado nas diferenças percebidas entre os sexos, e o gênero é uma forma primeira de significar as relações de poder”. Em relação ao gênero como elemento fundamentado segundo as diferenças notadas entre os sexos, a autora acredita que um dos elementos que sustentam essa definição é o conceito normativo expresso normalmente em doutrinas educativas, políticas, religiosas e jurídicas sobre o sentido do masculino e feminino, em que afirmam, categoricamente, que sejam contrários, dando ênfase ao sentido dos símbolos que podem impedir de visualizar alternativas, sendo assim, apresentado apenas com tal sentido. No entanto, a construção da história a partir desses caráteres dominantes, é repassada como uma consequência em que, socialmente, todos estivessem de acordo. Nesta ótica, a mulher é caracterizada como a do lar, a cuidadora, frágil, subjetiva e emocional, enquanto o homem é o provedor, forte, objetivo e direto (SCOTT, 1995; BOURDIEU, 2002).

\footnotetext{
${ }^{1}$ Linguística, letras, artes e humanas 


\section{A PRESENÇA DE DOCENTES MULHERES EM CARGOS GERENCIAIS NAS UNIVERSIDADES FEDERAIS DO ESTADO DE MINAS GERAIS \\ DOI: http://dx.doi.org/10.5007/1983-4535.2016v9n2p49}

Tais atribuições são decorrentes da percepção dos papéis da mulher, como dona de casa, mãe e esposa, no exercício de atividades domésticas, e do homem, o papel de mantenedor do lar, o que trabalha fora e mantêm a família. Contudo, muitas vezes, não se tem dimensão de tal separação entre os gêneros, sendo isso tratado a partir da naturalização dos papéis que se espera para homens e mulheres nas relações sociais cotidianas (STEIN, 1999; BOURDIEU, 2002; CAPPELlE, MELO e SOUZA, 2013). Consequentemente, uma sociedade segmentada é construída e reconstruída ao longo do tempo, guiada por normas e valores determinados para o homem e para a mulher. Isso se reproduz nas organizações, especialmente, na vida das mulheres, que podem sentir um pouco mais tais efeitos, considerando o conceito de que esse espaço não é seu "habitat natural", ou ainda, que tais concepções estejam tão naturalizadas, que as próprias mulheres não percebem as desigualdades existentes (CAPPELLE, MELO e SOUZA, 2013).

Acerca das relações de gênero nas organizações, Cappelle et. al (2004, p. 6) afirmam que "devem ser consideradas como práticas discursivas que refletem e distribuem manifestações de poder e resistência entre as pessoas, de acordo com os interesses dos grupos que se organizam e se enfrentam em campos de disputas sociais”. Já, o poder, segundo Melo (1985, p. 162) "é uma característica fundamental e inelutável de todas as relações sociais" e as “relações de trabalho tornam-se, na prática, o 'locus' privilegiado de manifestações das relações de poder, assumindo formas diversas de expressão conforme as relações de força existente entre os grupos de interesse na sociedade e na própria empresa" (MELO, 1991, p. 54). Desse modo, a reprodução e manutenção de condutas dentro da organização, que favoreçam ao homem e o coloquem em posição central são possibilitados, sobretudo, em um ambiente historicamente de predomínio masculino, em que, geralmente, as relação de poder são assimétricas (OAKLEY, 2000). Para facilitar o entendimento, o autor exemplifica a união por parte dos executivos para manutenção dos escalões superiores com predominância masculina. Segundo Velho (2006), no contexto universitário, na ocupação de cargos de alto escalão, há maior concorrência por postos de poder, resultando em um dos mais difíceis obstáculos para que as mulheres ascendam profissionalmente.

Diante desse cenário, percebe-se que, além do importante papel das instituições como a família, a igreja e o Estado, as escolas também representam poderoso instrumento na construção da visão e da conduta de alunos e alunas, que pode tanto colaborar para o fortalecimento da divisão sexual existente na sociedade, e, consequentemente, no meio 


\title{
A PRESENÇA DE DOCENTES MULHERES EM CARGOS GERENCIAIS NAS UNIVERSIDADES FEDERAIS DO ESTADO DE MINAS GERAIS \\ DOI: http://dx.doi.org/10.5007/1983-4535.2016v9n2p49
}

produtivo, quanto amenizá-la (BOURDIEU, 2002). Em relação à educação básica e média no Brasil, onde ocorre a socialização secundária, Andrade e Barros (2009) destacam que as escolas exercem papel importante na construção social sobre as percepções dos papéis de gênero das crianças e adolescentes, principalmente, quando não atuam de forma concreta para amenizar as visões existentes, seja na escola ou mesmo fora dela, e quando estimulam os estereótipos, uma vez que potencializam as diferenças sexuais socialmente construídas. Dentro desse contexto, na educação superior, os estudantes

\begin{abstract}
[...] muitas vezes (ou seja, nem sempre) escolhem os cursos superiores que irão frequentar e as profissões que desejam seguir com base em estereótipos de gênero (uma tendência à fragilização das fronteiras entre cursos e carreiras masculinas e femininas pode ser observada sem, contudo, indicar alterações profundas nos paradigmas existentes) (ANDRADE; BARROS, 2009, p. 100).
\end{abstract}

Assim, os modelos estereotipados podem contribuir para a escolha da profissão, tanto do homem quanto da mulher e também para consolidar e perpetuar esse tipo de concepção (SWAIN, 2001; OLINTO, 2011). Segundo Fonseca (2000), as atividades femininas, tradicionalmente, estão relacionadas a profissões como de secretárias, recepcionistas e auxiliares administrativos, formando assim um dos "guetos" que os atributos para exercício dessas funções estão ligados ao sensível, intuitivo e emocional.

$\mathrm{Na}$ área das ciências no Brasil, também se percebe uma divisão entre os sexos nas carreiras de exatas e da saúde, em que prevalece a presença masculina nas ciências exatas (física, matemática e engenharias), e da feminina nas ciências da saúde (ciências da saúde e biológicas), como identificado por Olinto (2011).

Portanto, apesar de, numericamente, mais presentes no espaço público e em diversos contextos, as mulheres, podem estar concentradas em áreas específicas, formando "guetos". Da mesma forma, tal cenário pode ser observado no mercado de trabalho, influenciando, de alguma maneira, nas ocupações das mulheres, sobretudo, em cargos e posições nas organizações.

\subsection{MULHERES E O TRABALHO: DIFICULDADES E DESAFIOS NAS ORGANIZAÇÕES}

Bourdieu (2002) acredita que a distinção entre homens e mulheres foi construída socialmente, baseada na diferença sexual de seus corpos. Desta forma, a representação da

\footnotetext{
${ }^{2}$ Segundo dicionário Aurélio: I. Bairro em que outrora os judeus eram obrigados a residir, nas cidades europeias; II. Local onde uma minoria está separada do resto da sociedade; III. Isolamento; IV. Carência de liberdade.
} 


\section{A PRESENÇA DE DOCENTES MULHERES EM CARGOS GERENCIAIS NAS UNIVERSIDADES FEDERAIS DO ESTADO DE MINAS GERAIS \\ DOI: http://dx.doi.org/10.5007/1983-4535.2016v9n2p49}

mulher tinha como base o corpo do homem como direcionador, que o autor chamou de princípio masculino. Assim, para o autor, o espaço público se construiu socialmente como espaço masculino, enquanto a mulher ficou associada ao ambiente privado, o lar. Ainda que as mulheres não tenham deixado de participar do meio público, mas nesse contexto, não tinham voz, ou seja, não eram consideradas, pelo menos no que diz respeito ao ocidente (PERROT, 2012). A partir do momento que tomaram consciência de das desigualdades vivenciadas em relação aos homens, surgem os movimentos feministas no fim do século XVIII, que ganham força no século XIX, em muitos países europeus e nos Estados Unidos (SARDENBERG; COSTA, 1994). Dessa forma, as mulheres têm alcançados espaços, e as políticas que buscam tratamentos igualitários maior visibilidade, o que pode contribui também para sua presença no mercado de trabalho.

Para Hirata e Kergoat (2008, p. 266) a divisão sexual do trabalho "é a forma de divisão trabalho decorrente das relações sociais entre os sexos; mais do que isso, é um fato prioritário para a sobrevivência da relação social entre os sexos". Com base nesse conceito, as autoras consideram que há dois princípios dentro da divisão do trabalho, o princípio da separação e o princípio hierárquico, o primeiro distingue que há trabalhos de homens e trabalhos de mulher, o segundo, que um trabalho de homem "vale" mais que um trabalho da mulher. Tais princípios permitem observarmos que, algumas décadas atrás, a estrutura de mercado de trabalho para as mulheres, constituiu-se como uma ampliação do meio doméstico (D’ALONSO, 2008), resultado da construção social com base na separação entre privado (mulher) e público (homem). Isso definiu, de certa forma, a mão de obra das mulheres como desqualificada, justamente por se entender que não eram capacitadas para exercer atividades que não fossem tradicionalmente tidas como "femininas", como cargos de liderança (BOURDIEU, 2002, HEILMAN et al., 1989). Assim, pode-se dizer que a precarização do trabalho da mulher no meio produtivo se deve, também, à visão de que o homem, especialmente no meio público, era mais capacitado para o trabalho do que a mulher.

Segundo Hirata (2009), observa-se um crescente aumento no emprego assalariado e do trabalho remunerado pelas mulheres, seja no setor formal, informal ou de serviços, contudo, verifica-se uma bipolarização do trabalho executado por mulheres, pois, de um lado, há mulheres em cargos executivos, em categorias que tem se feminizado (jornalistas, professoras universitárias, pesquisadoras, médicas, juízas, etc), do outro, a concentração de mulheres que permanecem em profissões tradicionalmente femininas (auxiliares de enfermagem, 


\section{A PRESENÇA DE DOCENTES MULHERES EM CARGOS GERENCIAIS NAS UNIVERSIDADES FEDERAIS DO ESTADO DE MINAS GERAIS \\ DOI: http://dx.doi.org/10.5007/1983-4535.2016v9n2p49}

professoras primárias, profissionais que atendem idosos, crianças e doentes, faxineiras, empregadas domésticas, etc). Dessa forma, "não se trata da exclusão da mulher dos quadros administrativos, mas de uma inserção subalterna" (CAPPELLE, MELO e SOUZA, 2013, p. 618). Assim, a forma de atuação no mercado de trabalho das mulheres tem se modificado, mas parece que a relação de hierarquia, em muitos casos, principalmente, em relação aos homens, ainda permanece. Desse modo, apesar de as mulheres estarem se inserindo em posições de maior destaque nas organizações, ainda enfrentam alguns desafios/dificuldades, tanto profissionais quanto pessoais.

Uma das dificuldades pode ser a maternidade, que para a mulher pode ser vista na organização como um fator negativo. Como identificado por Miranda et. al. (2009) no relato de uma docente em cargo de gerência de uma universidade federal, ficou evidenciado o preconceito dos colegas quando ela ficou grávida, deixando transparecer que o homem é mais produtivo, pois continua "produzindo", enquanto a mulher "deixa de produzir" no período em que está de licença. Por outro lado, Neto, Tanure e Andrade (2010) identificaram que algumas mulheres em postos de alta gerência têm prorrogado a maternidade, deixando para ter filhos depois dos 30 anos em prol de sua carreira, pois, no período anterior, geralmente, as mulheres estão em ascensão profissional, o que pode demandar maior tempo tanto no trabalho, quanto em sua formação. Na pesquisa de Deem (2003), em que foram entrevistados mulheres e homens docentes em cargos gerenciais de 16 universidades do Reino Unido, a pesquisadora constatou que $68 \%$ dessas docentes pensam que o fato de ser mulher afetou suas carreiras, e um dos motivos observados é a questão da maternidade, que influenciou não só as mulheres que já são mães, mas também aquelas que ainda não têm filhos, uma vez que ser mulher é suficiente para que sejam associadas à maternidade, e nesse contexto visto negativamente na organização.

Outro fator que para algumas mulheres ainda é realidade, é o fato de as atividades domésticas ainda serem atribuídas a elas, que além de aumentar a jornada de trabalho, precisam se adaptar a essa situação. Além da sobrecarga que pode gerar para a mulher (NETO; TANURE; ANDRADE, 2010), em várias áreas e posições, como nos cargos de gerência, normalmente, as mulheres precisam dedicar mais de seu tempo com o trabalho, o que pode ocasionar conflitos na família, uma vez que há uma articulação do mundo do trabalho com mundo privado (MIRANDA et. al., 2009, CANGIANI; MONTES, 2010). Percebe-se, assim, que, mesmo que as responsabilidades com a maternidade e com as 


\section{A PRESENÇA DE DOCENTES MULHERES EM CARGOS GERENCIAIS NAS UNIVERSIDADES FEDERAIS DO ESTADO DE MINAS GERAIS \\ DOI: http://dx.doi.org/10.5007/1983-4535.2016v9n2p49}

atividades domésticas sejam tanto do homem como da mulher, na prática, normalmente, as mulheres ainda ficam encarregadas de conciliar tais responsabilidades com a vida profissional (HIRATA; KERGOAT, 2007).

Outro elemento que pode estar presente no contexto organizacional é a dificuldade das mulheres de alcançarem os níveis mais altos das organizações, não por falta de habilidade e/ou competência, porque em algumas organizações elas podem estar em cargos de baixa gerência, mas tal obstáculo se deve pelo seu sexo, ou seja, por ser mulher. Esse fenômeno é conhecido como "teto de vidro"3 (STEIL, 1997). Segundo Steil (1997), esse bloqueio ocorre de maneira tão suave, que a mulher, muitas vezes, toma para si como algo natural, não percebendo a força contrária que essa barreira causa à sua ascensão profíssional.

Já a segregação horizontal restringe a presença das mulheres a certas profissões (CAPPELlE, MELO e SOUZA, 2013), são os formados por "guetos" femininos e masculinos. Para Olinto (2011), esses tipos de segregação é a expressão das diferenças de habilidades e características entre homens e mulheres, e pode esclarecer a restrição a algumas ocupações pelas mulheres e os obstáculos enfrentados para se alcançar cargos de destaques na hierarquia organizacional e também elucidaria as diferenças de gênero no campo acadêmico.

\section{PROCEDIMENTOS METODOLÓGICOS}

Esta pesquisa é de natureza quantitativa, de caráter descritivo. Para a coleta de dados, inicialmente, entrou-se em contato com o MEC para que fossem disponibilizados os dados sistematizados dos docentes gerentes das onze universidades federais de Minas Gerais, quais sejam, Universidade Federal de Minas Gerais (UFMG), Universidade Federal de São João Del Rey (UFSJ), Universidade Federal de Uberlândia (UFU), Universidade Federal de Juiz de Fora (UFJF), Universidade Federal de Lavras (UFLA), Universidade Federal de Itajubá (UNIFEI), Universidade Federal de Ouro Preto (UFOP), Universidade Federal do vale do Jequitinhonha e Mucuri (UFVJM), Universidade Federal do Triângulo Mineiro (UFTM), Universidade Federal de Alfenas (UNIFAL) e Universidade Federal de Viçosa (UFV). No entanto, os responsáveis retornaram o contato informando que não possuíam esses dados sistematizados. Por isso, foram extraídos todos os dados necessários nos sites de cada uma das instituições pesquisadas, durante o ano de 2012. Assim, os pesquisadores acessaram os sites

\footnotetext{
3 “Esse conceito foi inserido na década de 80 nos Estados Unidos, e descreve uma barreira que, de tão sutil, é transparente, mas suficientemente forte para impossibilitar a ascensão de mulheres a níveis mais altos da hierarquia organizacional" (Steil, 1997, p. 62).
} 


\section{A PRESENÇA DE DOCENTES MULHERES EM CARGOS GERENCIAIS NAS UNIVERSIDADES FEDERAIS DO ESTADO DE MINAS GERAIS \\ DOI: http://dx.doi.org/10.5007/1983-4535.2016v9n2p49}

principais das instituições, de suas pró-reitorias, dos programas de pós-graduação strictu sensu, dos cursos de graduação presenciais, das faculdades, escolas, institutos e departamentos. Por isso, uma limitação da pesquisa refere-se à possibilidade de tais dados poderem estar desatualizados, ou mesmo incorretos no momento em que foram extraídas. Algumas informações não estavam disponíveis nos sites das instituições, portanto, buscou-se contato via e-mail e por telefone com os departamentos responsáveis, para complementação das informações.

Em relação aos cargos de pró-reitores, observou-se que alguns eram ocupados por técnicos administrativos, por isso, optou-se nessa pesquisa por considerar somente os ocupantes de cargos gerenciais que também fossem professores. A classificação de cargos utilizada para esta pesquisa foi de baixa gerência: coordenador(a) de pós-graduação strictu sensu e coordenador(a) de graduação (modalidade presencial), chefia/diretor departamento, e, alta gerência: reitor(a); pró-reitor(a); chefe de gabinete; diretor de instituto/faculdade. Nos cargos de baixa gerência a remuneração para o desempenho da função é bem mais baixa (em torno de $\mathrm{R} \$ 804,00$ a mais no salário) ${ }^{4}$ que nos cargos de alta gerência (valores em torno de $\mathrm{R} \$ 3177,00$ e R\$ 6667,00 a mais no salário), esse foi um parâmetro para a classificação dos cargos nessas duas categorias.

As áreas acadêmicas a quem pertencem os professores que ocupam cargos gerenciais foram organizadas em seis grandes áreas com base na divisão utilizada pela CAPES: 1) Humanas; 2) Exatas e da Terra; 3) Ciências Sociais Aplicadas; 4) Ciências da Saúde e Biológicas; 5) Ciências Agrárias e 6) Engenharias.

Os dados secundários coletados foram analisados a partir das distribuições de frequência, apresentadas nos gráficos a seguir.

\section{RESULTADOS E DISCUSSÕES}

Para apresentar os resultados da pesquisa foram criadas duas categorias de análise, 1) Guetos, áreas e gerência universitária e 2) Níveis gerenciais e a presença de mulheres, que tratam das ocupações das docentes gerentes, sob a ótica das relações de gênero no âmbito universitário.

\footnotetext{
${ }^{4}$ Valores com base na Lei n ${ }^{\mathrm{o}} 12.778$, de 28 de dezembro de 2012, anexos I e III da Lei no 11.526/2007 (atualização de 01/01/2015).
} 


\section{A PRESENÇA DE DOCENTES MULHERES EM CARGOS GERENCIAIS NAS UNIVERSIDADES FEDERAIS DO ESTADO DE MINAS GERAIS \\ DOI: http://dx.doi.org/10.5007/1983-4535.2016v9n2p49}

Segundo Leta (2003) há um cenário de mudanças nas últimas décadas, em que as mulheres aumentaram sua frequência nas universidades brasileiras, chegando a ser numericamente superiores na graduação e pós-graduação. Porém, não se percebe a mesma situação no que diz respeito à ocupação de cargos gerenciais, principalmente, nos níveis mais altos da hierarquia (VAZ, 2013) e em algumas áreas da ciência. Nessa perspectiva, a partir dos dados coletados e diante dos conceitos e discussões do arcabouço teórico apresentado, buscou-se, também, refletir se esse movimento na pós-graduação tem se refletido nos cargos de gestão das universidades federais do estado de Minas Gerais, uma vez que também é crescente a participação das mulheres em cargos de gerência no Brasil, como identificado por Melo (2003).

Dessa forma, para iniciar as análises dos resultados, serão apresentados dados que se referem à presença de docentes gerentes nos cargos gerenciais de cada universidade federal pesquisada.

\subsection{GUETOS, ÁREAS E GERÊNCIA UNIVERSITÁRIA}

Nessa primeira categoria de análise, os resultados e as discussões giram em torno da ocupação de cargos gerenciais por docentes, à luz das relações de gênero, no que diz respeito ao contexto das universidades em que estão inseridos, juntamente com questões que envolvem possíveis influências dos estereótipos de gênero construídos socialmente e em relação às áreas acadêmicas. Para tanto, o primeiro gráfico apresenta o percentual de mulheres e homens docentes, em cada universidade pesquisada.

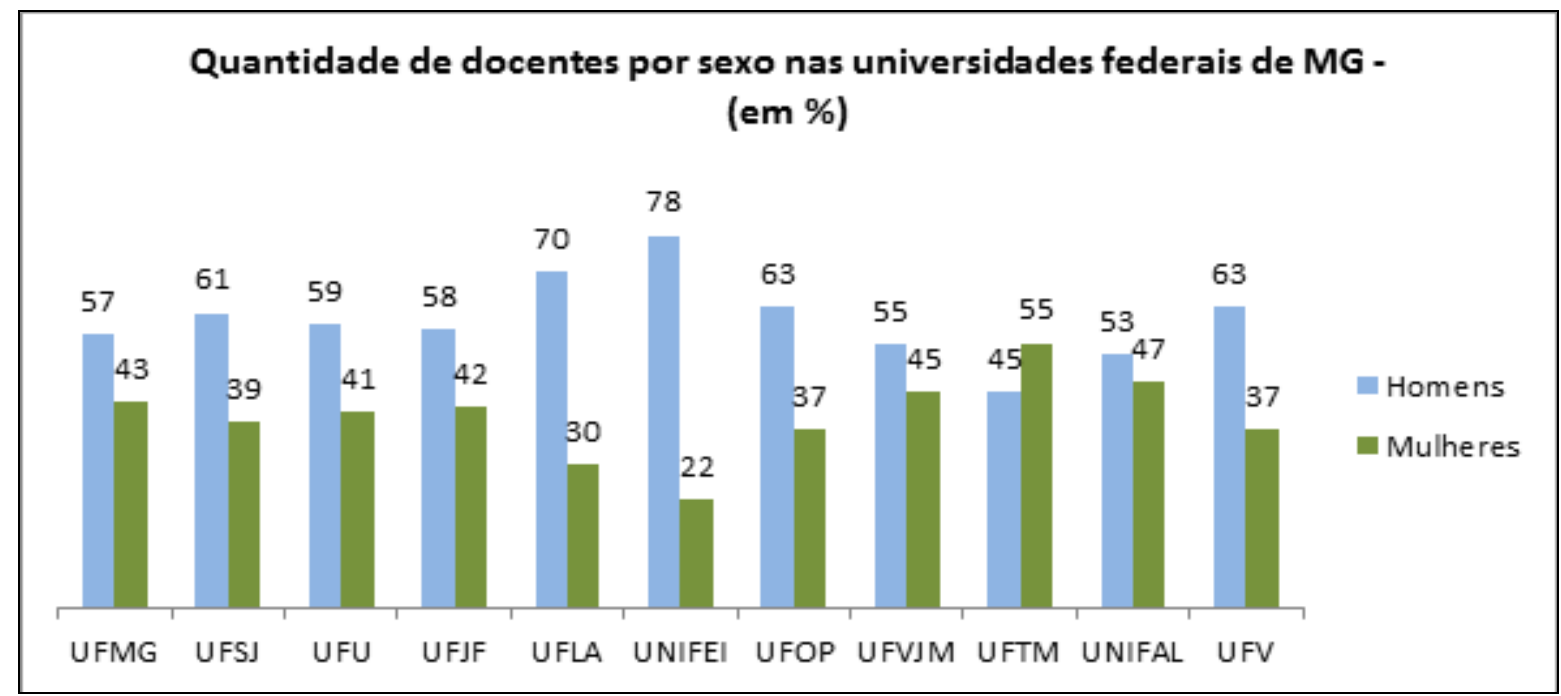

Gráfico 1 Quantidade de docentes por sexo nas universidades de MG Fonte: Dados da pesquisa 


\section{A PRESENÇA DE DOCENTES MULHERES EM CARGOS GERENCIAIS NAS UNIVERSIDADES FEDERAIS DO ESTADO DE MINAS GERAIS \\ DOI: http://dx.doi.org/10.5007/1983-4535.2016v9n2p49}

Percebe-se que os docentes homens são a maioria numérica em todas as universidades, exceto, na UFTM. No que se refere à diferença de percentual entre docentes homens e docentes mulheres de cada universidade, percebe-se que são maiores na UNIFEI (56\%), UFLA (40\%), UFV e UFOP (26\%). Por outro lado, a UFTM é a única universidade federal com maior presença de docentes mulheres, visto que elas representam $10 \%$ a mais que os homens. A UNIFAL, UFVJM e UFMG apresentam menores distâncias entre homens e mulheres docentes, $6 \%, 10 \%$ e $14 \%$, respectivamente.

O próximo gráfico expõe o percentual dos docentes por sexo, que estão em cargos gerenciais. Adiante, será possível perceber se a presença de docentes mulheres em cargos gerenciais segue a mesma proporcionalidade da presença delas nas instituições.

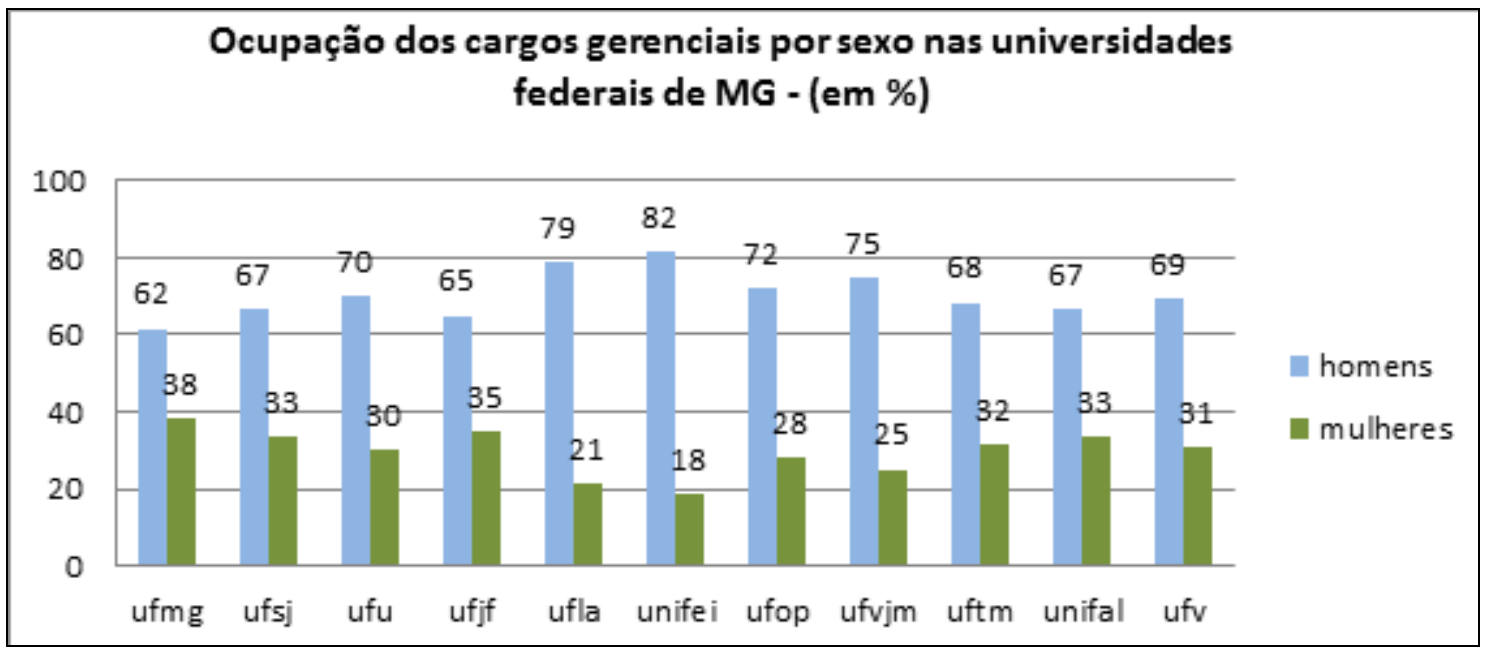

Gráfico 2 Ocupação dos cargos gerenciais nas universidades federais de $\mathrm{MG}$ Fonte: Dados da pesquisa

No gráfico 2, observa-se que, em todas as universidades pesquisadas, os homens são maioria numérica na gerência dessas instituições, mesmo na UFTM, como mostrado no gráfico anterior, em que as mulheres são a maioria numérica como docentes.

Ainda que os docentes sejam a maioria numérica no cargo de direção, a proporção entre homens e mulheres varia entre as universidades. Com base no contexto histórico das universidades, observa-se que naquelas que foram constituídas a partir de cursos em que, tradicionalmente, havia maior concentração da presença masculina, a tendência é ter maior percentual de docentes homens na gerência, como na UFLA e UNIFEI, originados, respectivamente, da Escola Agrícola de Lavras e do Instituto Eletrotécnico e Mecânico (10 Escola de Engenharia a se instalar no Brasil). O primeiro curso oferecido pela UFLA foi de 


\section{A PRESENÇA DE DOCENTES MULHERES EM CARGOS GERENCIAIS NAS UNIVERSIDADES \\ FEDERAIS DO ESTADO DE MINAS GERAIS \\ DOI: http://dx.doi.org/10.5007/1983-4535.2016v9n2p49}

agronomia, que contava com a presença essencialmente de homens. A UNIFEI, que sempre ofereceu cursos de engenharia elétrica e mecânica, também se apresenta como uma universidade que desde seu início teve o predomínio da presença masculina. Um movimento parecido ocorre nas universidades que tiveram em sua origem, cursos com maior presença feminina, como a UFMG, com a Faculdade de Direito e Escola Livre de Odontologia; a $\mathrm{UFJF}^{5}$, com a Faculdade de Odontologia e a Faculdade de Direito; e a UNIFAL, com a Escola de Farmácia e Odontologia de Alfenas. Já, na UFTM, percebe-se uma situação diferenciada, como ela se originou da Faculdade de Medicina do Triângulo Mineiro, apesar de pertencer a uma área de "gueto feminino", a medicina é um curso tradicionalmente masculino.

Outra possibilidade de reflexão sobre os baixos percentuais da presença de docentes mulheres na gerência universitária, é que estes cargos (principalmente, cargos reitoria e próreitoria), normalmente, são exercidos por docentes de idade um pouco mais avançada, pois, diferentemente de organizações privadas que, atualmente, tendem a favorecer os mais jovens, a experiência e o tempo de trabalho são fatores de grande relevância para a ocupação dessas posições, especialmente, nos cargos de alta gerência, conforme aponta Miranda (2010). A pesquisa deste autor evidenciou que as docentes gerentes entrevistadas tinham idade entre 35 e 60 anos, e que a maioria tinha 50 anos ou mais. Essa reflexão é importante, pois a participação de mulheres como docentes em universidades brasileiras se intensificou a partir dos anos de 1980 e 1990 (LETA, 2003), movimento recente. Além disso, a formação dos "guetos" tem se modificado ao longo do tempo, mesmo com a presença tímida das mulheres nos cargos de chefia em relação aos homens, percebe-se que a diferença é nítida em comparação com 20/30 anos atrás (TANURE, CARVALHO NETO e ANDRADE, 2007).

Para completar a análise, também foram levantados dados que possibilitassem uma discussão a respeito da distribuição dos docentes gerentes por área de atuação. Isso será possível, a partir da observação do gráfico a seguir.

\footnotetext{
${ }^{5}$ A informação sobre as primeiras faculdades/institutos desta instituição não está disponível diretamente no histórico do site da principal da universidade, porém nas páginas que dão acesso aos institutos e faculdade, foi possível acesso sobre a criação das faculdades e instituto, dessa forma, entendeu-se que, primeiro foi criada a Escola de Odontologia (1904) e alguns anos mais tarde, a Escola de direito (1934) teve a reabertura do curso.
} 


\section{A PRESENÇA DE DOCENTES MULHERES EM CARGOS GERENCIAIS NAS UNIVERSIDADES FEDERAIS DO ESTADO DE MINAS GERAIS \\ DOI: http://dx.doi.org/10.5007/1983-4535.2016v9n2p49}

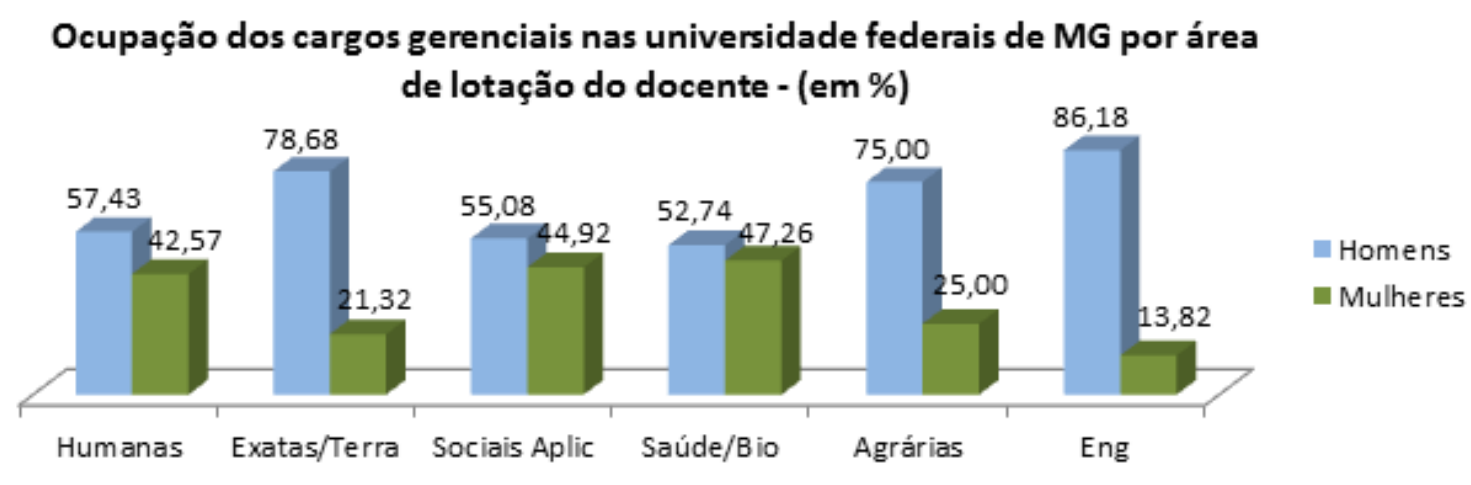

Gráfico 3 Ocupação dos cargos gerenciais nas universidades federais de MG por área de lotação do docente Fonte: Dados da pesquisa

No gráfico 3, em que a ocupação de cargos gerenciais está por área de lotação do docente, os homens também estão em maioria numérica em todas as universidades federais de MG, mesmo em áreas tradicionalmente femininas.

Dessa forma, a análise dos dados mostra que a construção social do gênero, pode influenciar na distribuição dos docentes, no que diz respeito às áreas acadêmicas que atuam, uma vez que nas áreas de saúde/biológicas, humanas e ciências sociais aplicadas, a proporção de docentes mulheres é, em média, cerca de 45\%. Nas outras áreas, o percentual da presença delas é, em média, cerca de $20 \%$. Esses resultados vão ao encontro dos apresentados por Olinto (2011), em que foi constatada a predominância de mulheres nas ciências da saúde e, dos homens, nas ciências exatas, como professores(as) / pesquisadores(as). Tais constatações revelam que, no Brasil, a ascensão na carreira das mulheres, ainda pode ser limitada ou direcionada, ou seja, voltada para as áreas em que elas já estão concentradas.

Nesse contexto, docentes homens parecem encontrar pouca dificuldade em ocupar cargos gerenciais em áreas tradicionalmente femininas. Por outro lado, as docentes em cargos de gerência que atuam em áreas de guetos masculinos (engenharia, agrárias e exatas) podem encontrar mais dificuldades na ocupação desses tipos de cargo do que as docentes em funções gerenciais nas áreas de ciências da saúde, por exemplo, ainda que, como apresentado, a proporção total de docentes homens em relação às docentes mulheres seja próxima. Tais dados podem reforçam a ideia de que há áreas ou trabalhos mais voltados para homens e outros para mulheres, principalmente, o gerencial. 


\section{A PRESENÇA DE DOCENTES MULHERES EM CARGOS GERENCIAIS NAS UNIVERSIDADES FEDERAIS DO ESTADO DE MINAS GERAIS \\ DOI: http://dx.doi.org/10.5007/1983-4535.2016v9n2p49}

\subsection{NÍVEIS GERENCIAIS E A PRESENÇA DE MULHERES}

As análises dessa categoria partem da observação das posições ocupadas pelos (as) docentes no exercício da gerência universitária, buscando identificar se há desigualdades nos níveis gerenciais e possíveis tendências em relação ao movimento que diz respeito à presença das mulheres no mundo acadêmico. No gráfico a seguir serão apresentadas as ocupações dos cargos de baixa e alta gerência.

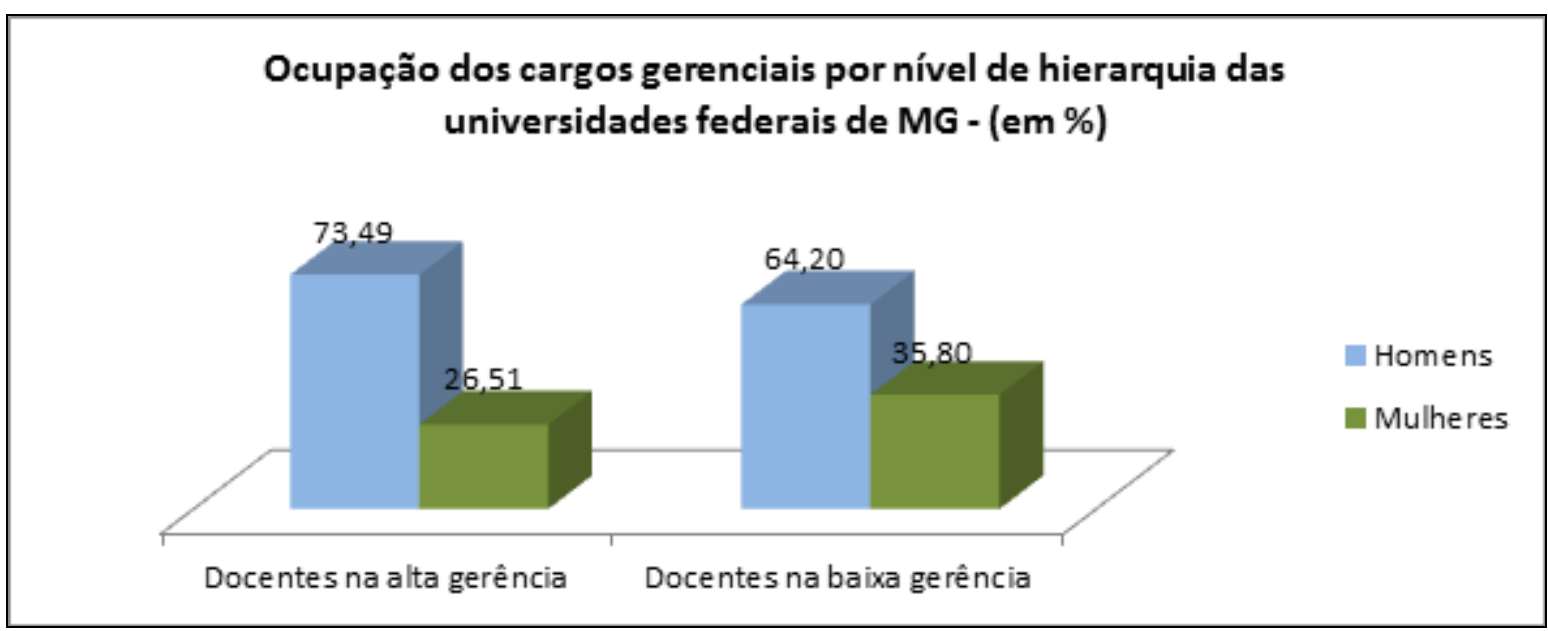

Gráfico 4 Ocupação dos cargos gerenciais por nível de hierarquia nas universidades federais do estado de $\mathrm{MG}$ Fonte: Dados da pesquisa

No gráfico 4 observa-se que as desigualdades entre docentes mulheres e homens nos cargos gerenciais são bem marcantes, sobretudo, nos postos considerados de maior privilégio, como os cargos de alta gerência.

$\mathrm{Na}$ maioria das vezes, os cargos de alta gerência exigem maior experiência na gestão, por isso, quem os ocupou, normalmente, já passou por algum cargo da hierarquia anterior (baixa gerência). No contexto da gestão universitária, como os cargos de maior nível hierárquico são comissionados, a indicação geralmente é dada pela autoridade maior da instituição, que decide sobre a ocupação desses cargos de maior prestígio. Não é a regra, mas é comum que o reitor escolha alguém que já tenha experiência na baixa gerência.

Nesse cenário, as relações de poder operam no sentido de influenciar na maior disputa por cargos de nível alto na hierarquia, seja por status, ou mesmo pelo próprio poder que a posição pode lhe conferir, pela intimidação de um grupo em relação ao outro, ou ainda pela remuneração, pois além de propiciar influência, um cargo de pró-reitor remunera significantemente mais do que de coordenador de graduação. Assim, nesses cargos mais 


\section{A PRESENÇA DE DOCENTES MULHERES EM CARGOS GERENCIAIS NAS UNIVERSIDADES FEDERAIS DO ESTADO DE MINAS GERAIS \\ DOI: http://dx.doi.org/10.5007/1983-4535.2016v9n2p49}

"visados", as disputas de poder também são maiores e ocorrem, muitas vezes, de forma assimétrica tornando a ocupação dos cargos de alta gerência predominantemente por homens. Essa argumentação vem ao encontro do que foi identificado por Miranda (2010) na universidade pesquisada, em que foi observada a predominância masculina desde o princípio da instituição, o que pode colaborar para a manutenção dos mesmos, sobretudo, nos cargos de alta gerência. Dessa forma, vale lembrar que a expansão da escolaridade e o ingresso nas universidades no Brasil, pelas mulheres, ocorreram no final do século XX (BRUSCHINI e PUPPIN, 2004). Esse "atraso" pode ter colaborado para a menor presença delas nas universidades federais pesquisadas e, consequentemente, para a pouca experiência na gerência universitária, que pode repercutir na menor oportunidade de ocupar postos de alta gerência nas instituições.

Além disso, o menor acesso das mulheres aos cargos de alta gerência pode ocorrer devido ao fenômeno conhecido como "teto de vidro", que dificultaria a presença de mulheres, principalmente, aos cargos de nível alto, justamente pelo seu sexo e não pela falta de habilidades e/ou competência (STEIL, 1997), e assim podendo evidenciar preconceito e discriminação contra mulheres nas instituições pesquisadas. Alguns trabalhos reforçam o argumento de quanto mais alto o posto de trabalho, menor a participação de mulheres, como constatou Olinto (2011), com base na distribuição das bolsas acadêmicas ofertadas pelo CNPq, que as bolsas de iniciação científica têm maior parcela de mulheres, chegando a representar quase $56 \%$, ao contrário das bolsas de produtividade em pesquisa - de maior prestígio no meio acadêmico - em que os homens são a maioria, representando $65 \%$. No trabalho de Vaz (2013), a autora reuniu evidências que indicam que, ainda que a entrada no setor público seja por meio de concurso, em relação às carreiras, o espaço público brasileiro não está imune ao fenômeno teto de vidro. Essa perspectiva pode ser apoiada a partir da análise do gráfico 5 . 


\section{A PRESENÇA DE DOCENTES MULHERES EM CARGOS GERENCIAIS NAS UNIVERSIDADES \\ FEDERAIS DO ESTADO DE MINAS GERAIS \\ DOI: http://dx.doi.org/10.5007/1983-4535.2016v9n2p49}

\section{Ocupação dos cargos por docentes das universidades federais de MG - (em \%)}

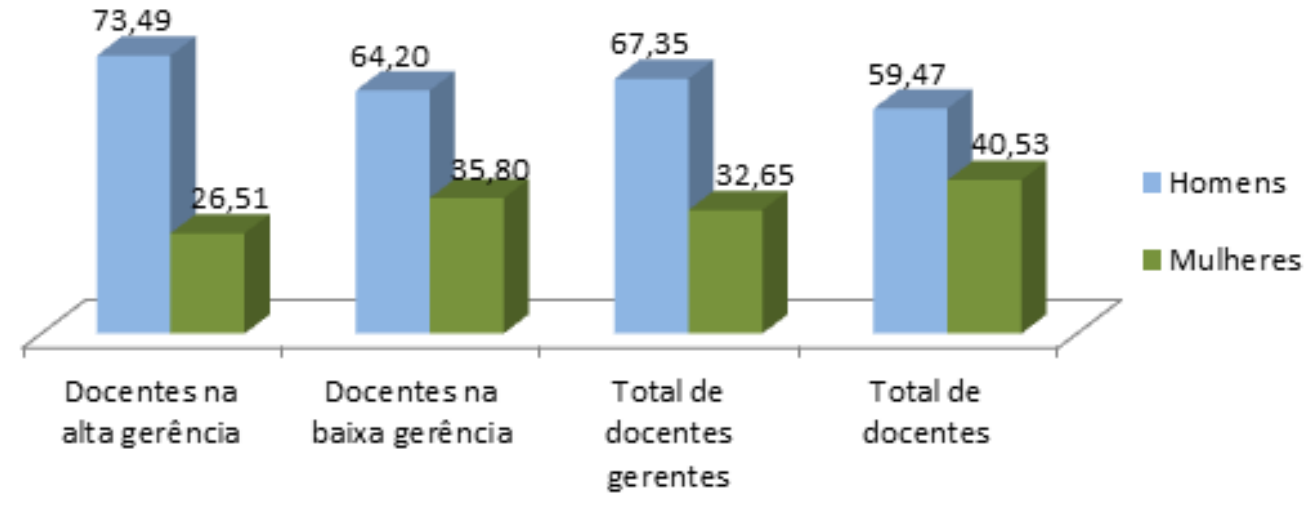

Gráfico 5 Ocupação dos cargos por docentes nas universidades federais de MG. Fonte: Dados da pesquisa.

O gráfico 5 confirma que a presença de docentes homens se destaca em todos os níveis de ocupação de cargos das universidades pesquisadas, principalmente, nos cargos de alta gerência. Isso quer dizer que há desigualdade numérica em relação ao sexo. Por outro lado, considerando que o espaço público, por muito tempo, foi um espaço de predominância dos homens (o que não significa dizer que as mulheres não tiveram participação significativa nesse meio, uma vez que foram abafadas pela sociedade, pelo menos no ocidente (PERROT, 2012), tais dados podem demostrar que, depois de muitas reinvindicações e com as mudanças na sociedade, além da presença em outros setores da sociedade, as mulheres estão entrando nas universidades como docentes, e aos poucos têm ocupado cargos gerenciais.

\section{CONSIDERAÇÕES FINAIS}

A presente pesquisa foi realizada com o objetivo analisar a presença de docentes mulheres em cargos gerenciais nas universidades federais do estado de Minas Gerais. Através das fontes secundárias que foram sistematizadas, foi possível identificar que, nas onze universidades federais pesquisadas, os cargos gerenciais são ocupados em sua maioria por docentes homens, principalmente, em cargos de alto nível hierárquico. Entretanto, identificase que em cada universidade, as proporções de docentes mulheres em relação aos homens são diferentes, pois em áreas com concentração feminina, a presença das docentes gerentes é significativamente maior, quando comparada à presença delas em áreas com concentração masculina. 


\section{A PRESENÇA DE DOCENTES MULHERES EM CARGOS GERENCIAIS NAS UNIVERSIDADES FEDERAIS DO ESTADO DE MINAS GERAIS \\ DOI: http://dx.doi.org/10.5007/1983-4535.2016v9n2p49}

A pesquisa mostrou que o movimento iniciado pela crescente entrada das mulheres, tanto no meio produtivo, como no acadêmico (alunas e docentes), não tem se refletido na mesma proporção e nem no mesmo ritmo em cargos gerenciais. Assim, as mulheres docentes em cargos de gerência das universidades pesquisadas continuam enfrentando obstáculos, uma vez que as desigualdades ainda estão presentes nas relações sociais, se apresentando, muitas vezes, de forma implícita, pois os valores que direcionam as condutas estão normalmente enraizados, o que dificulta mudanças profundas na sociedade, além das relações estabelecidas que podem gerar assimetria de poder, favorecendo um dos lados, no caso dessa pesquisa, os docentes homens.

Desse modo, essa pesquisa torna-se importante, pois, por um lado, há muitos estudos acerca de docentes mulheres na pesquisa, mas, por outro lado, é escassa a literatura a respeito delas na gerência universitária. Nesse sentido, a pesquisa também pode ser fonte de dados e reflexões, por sua abordagem abrangente, pois considera todas as universidades federais de Minas Gerais.

\section{REFERÊNCIAS BIBLIOGRÁFICAS}

ARAÚJO, M. F. Diferença e igualdade nas relações de gênero: revisitando o debate.

Psicologia Clínica, Rio de janeiro, v. 17, n. 2, p. 41-52, 2005.

ANDRADE, C. R.; BARROS, A. N. Gênero e Educação: delimitação de espaços e construção de estereótipos. Contrapontos, Itajaí, v. 9, n. 2, p. 90-103, 2009.

BRASIL. Lei no 12.778 , de 28 de dezembro de 2012. Dispõe sobre a fixação de remuneração dos cargos e funções comissionadas da administração pública federal direta, autárquica e fundacional. Disponível em: < http://www.planalto.gov.br/ccivil 03/_Ato20112014/2012/Lei/L12778a.htm>. Acesso em 26 mai. 2015.

BOURDIEU, P. (1999). A dominação masculina. Tradução Maria Helena Kuhner. 2a Ed. Rio de Janeiro: Bertrand Brasil, 2002.

BRUSCHINI, C. Trabalho e gênero no Brasil nos últimos dez anos. Cadernos de Pesquisa, v. 37, n. 132, p. 537-572, 2007.

BRUSCHINI, C.; PUPPIN A. B. Trabalho de mulheres executivas no Brasil no final do século XX. São Paulo, Caderno Pesquisa, v. 34, n. 121, p. 105-138, 2004.

CAPPELLE, M. C. A., MELO, M. C. O. L., BRITO, M. J. M., BRITO, M. J. Uma análise da dinâmica do poder e das relações de gênero no espaço organizacional. RAE-Eletrônica, FGV-EAESP, São Paulo, v. 3, n. 2, 2004. 
CAPPELLE, M. C. A.; MELO, M. C. O. L.; SOUZA, N. L. Mulheres, Trabalho e Administração. Revista Interdisciplinar de gestão social, UFBA, v. 2, n. 2, p. 161-191, 2013.

CANGIANI, M. R.; MONTES, J. R. Mulher, maternidade e trabalho acadêmico.

Investigación y Educación en Enfermería. Universidad de Antioquia, v. 28, n. 2, p. 176$186,2010$.

CNPq. Plataforma Lattes, distribuição de pesquisadores por sexo, por faixa etária e grande

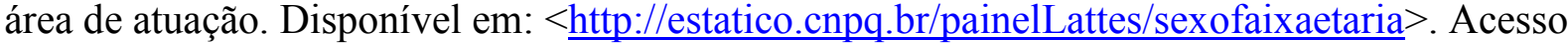
em: 13 abr. 2014.

D’ALONSO, G. L. Trabalhadoras brasileiras e a relação com o trabalho: trajetórias e travessias. Psicologia para América Latina, n. 15, México, 2008.

DEEM, R. Gender, Organizational Cultures and the practices of Manager: Academics in UK Universities. Gender, Work and Organization. v. 10, n. 2, p. 239-259, 2003.

FONSECA, T. M. G. Gênero, Subjetividade e Trabalho. Petrópolis, Rio de Janeiro: Vozes, 2000. 213 p.

FONSECA, T. M. G. (Org.). Mulher e cidadania na ordem social. São Paulo: Núcleo de Estudos da Mulher e Relações Sociais de Gênero/USP, 1996.

HEILMAN, M. E. C; BLOCK, C. J; MARTELL, R. F; SIMON, M. C. Has Anything Changed? Current Characterizations of Men, Women, and Managers. Journal of Applied Psychology, v. 74, n. 6, p. 935-942, 1989.

HIRATA, H. A precarização e a divisão internacional e sexual do trabalho. Sociologias. Porto Alegre, v. 11, n. 21, p. 24-41, 2009.

HIRATA, H. KERGOAT, D. Novas configurações da divisão sexual do trabalho. Cadernos de Pesquisa, v. 37, n. 132, p. 595-609, 2007.

HIRATA, H. KERGOAT, D. Divisão sexual do trabalho profissional e doméstico: Brasil, França, Japão. In: COSTA, A. O; SORJ, B; BRUSCHINI, C; HIRATA, H. (Orgs). Mercado de trabalho e gênero: comparações internacionais. Rio de Janeiro: Editora FVG, p. 263-278, 2008 .

LETA, J. As mulheres na ciência brasileira: crescimento, contrastes e um perfil de sucesso. Estudos Avançados, São Paulo, vol.17, n. 49, p. 271-284, 2003.

MELO, M. C. O. L. Participação como meio não institucionalizado de regulação de conflitos. In: FLEURY, M. T. L; FISCHER, R. M. F. (Orgs). Processo e relações do trabalho no Brasil: movimento sindical, comissão de fabrica, gestão e participação, o modelo japonês de organização da produção no Brasil. São Paulo: Atlas, p. 161-178, 1985. 
MELO, M. C. O. L. Estratégias do trabalhador informático nas relações de trabalho. Belo Horizonte: UFMG/FACE, 1991. 411 p.

MELO, M. C. O. L. A construção do espaço gerencial por mulheres brasileiras: comparando a gerência feminina em setores industrial e bancário. In: CONGRESO LATINOAMERICANO DE SOCIOLOGÍA DEL TRABAJO, 4., 2003, Havana. Anais eletrônicos... Havana: ALAST, 2003. CD-ROM.

MIRANDA, A. R. A. Um estudo sobre a dinâmica identitária de professoras gerentes de uma universidade pública. Dissertação de Mestrado em Administração. Lavras: UFLA, 2010 .

MIRANDA, A. R. A.; FONSECA, F. P.; CAPPELLE, M. C. A.; MAFRA, F. L. N.;MOREIRA, L. B. Professoras e Gerentes: Articulando Identidade e Gênero na Gestão Pública Executiva. In: Encontro da ANPAD, 33., São Paulo, 2009. Anais... São Paulo: EnANPAD, 2009.

NETO, A. C; TANURE, B; ANDRADE J. Executivas: carreira, maternidade, amores e preconceitos. RAE-Eletrônica, EAESP, São Paulo, v. 9, n. 1, 2010.

OAKLEY, J, G. Gender-based Barriers to Senior management positions: understanding the scarcity of female CEOs. Journal of Business Ethics, v. 27, n. 4, p. 321-334, 2000.

OLINTO, G. A inclusão das mulheres nas carreiras de ciência e tecnologia no Brasil. Inclusão Social, Brasília, DF, v. 5, n. 1, p.68-77, 2011.

PERROT, M. Minha história das mulheres. Trad. Ângela M. S. Corrêa. 2 ed. São Paulo, Contexto, 2012, 190 p.

PUPPIN, A. B. Mulheres em cargos de comando. In: BRUSCHINI, C; SORJ, B. (Org.). Novos olhares: mulheres e relações de gênero no Brasil. São Paulo: Fundação Carlos Chagas, 1994. Relatório Azul/POA: Assembleia Legislativa, 1995.

SARDENBERG, C. M. B; COSTA, A. A. A. Feminismos, feministas e movimentos sociais. In: BRANDÃO, M. L. R; BINGEMER, M. C. L. (Org.). Mulher e relações de gênero. São Paulo: Loyola, 1994. p. 77-89.

SCOTT, J. Gênero: uma categoria útil de análise histórica. Trad. Christine Rufino Dabat e Maria Betânia Ávila. Educação \& Realidade, v. 20, n. 2, p. 71-99, 1995.

STEIL, A. V. Organizações, gênero e posição hierárquica: compreendendo o fenômeno do teto de vidro. Revista de Administração, São Paulo, v. 32, n. 3, p. 62-69, 1997. Disponível em: < www.rausp.usp.br/download.asp?file=3203062.pdf> . Acesso em: 10 mai. 2014.

STEIN, R. Incesto e amor humano: a traição da alma na psicoterapia. Tradução de Cláudia Gerpe Duarte, São Paulo: Paulus, 1999. 
SWAIN, T. N. Feminismo e recortes do tempo presente: mulheres em revistas "femininas". São Paulo em Perspectiva, São Paulo, v. 15, n. 3, 2001.

TANURE, B; NETO, A. C; ANDRADE, J. Executivos: Sucesso e Infelicidade. $1^{\text {a }}$ ed. Rio de Janeiro. Ed. Campus/Elsevier. São Paulo, 2007.

VAZ, D. V. O teto de vidro nas organizações públicas: evidências para o Brasil. Economia e Sociedade, Campinas, v. 22, n. 3, p. 765-790, 2013.

VELHO, L. Prefácio. In: SANTOS, L. W dos; ISCHIKAWA, E. Y.; CARGANO, D. F. Ciência, tecnologia e gênero: desvelando o feminino na construção do conhecimento. Londrina: IAPAR, 2006. 